\title{
APRESENTAÇÃO: PROGRAMA DEMOCRACIAS EN REVOLUCIÓN, REVOLUCIONES EN DEMOCRACIA
}

\section{INTRODUTION TO THE PROGRAM DEMOCRACIES IN REVOLUTION, REVOLUTIONS ON DEMOCRACY}

\author{
Wagner Iglecias ${ }^{1}$ \\ Universidade de São Paulo, São Paulo (SP), Brasil
}

Resumo: Este texto apresenta o Programa Democracias en Revolución, Revoluciones en Democracia, iniciativa do governo do Equador para a promoção do debate sobre os governos de distintas correntes de esquerda ocorridos desde o início deste século na América Latina. Focando-se mais especificamente no caso brasileiro, este texto chama a atenção para os êxitos alcançados pelos governos do Partido dos Trabahadores, mas aponta também para as várias contradições inerentes a eles.

Palavras-chave: Democracia; Revolução; Brasil; Esquerdas.

Abstract: This text presentes the Democracies in Revolution, Revolutions in Democracy Program, whith is an iniciative of Equador government to promote the debate regarding the governemts of different left streams that existed since the beginning of this century in Latin America. Focusing more specifically on the Brazilian case, this text highlight the successes obtained by the governements leaded by the Labour Party, but also point to the various contradictions inherent to them.

Key-words: Democracy; Revolution; Brasil; Lefts.

\footnotetext{
${ }^{1}$ Doutor, Professor da Escola de Artes, Ciências e Humanidades da Universidade de São Paulo; Professor do Programa Interunidades em Integração da América Latina da Universidade de São Paulo. E-mail: <wi6@usp.br> Recebido em: 14.02.2016; aceito em: 11.06.2016.
} 


\section{INTRODUÇÃO}

O presente texto refere-se ao Programa Democracias en Revolución, Revoluciones en Democracia, iniciativa criada em 2013 pelo Ministério das Relações Exteriores da República do Equador para impulsionar nos meios acadêmicos, políticos, sociais e midiáticos latinoamericanos o debate relativo à dinâmica que resultou na chegada ao poder de forças políticas progressistas em diversos países da região a partir da virada para o século XXI e ao longo de sua primeira década. Em que pesem as distintas colorações dos governos que foram construídos no período na Venezuela, Brasil, Argentina, Uruguai, Bolívia, Equador, Nicarágua e El Salvador, é inegável que a onda vermelha que ocorreu nos últimos anos na América Latina constituiu-se em algo absolutamente inédito na História Política da nossa região. Daí a importância desta e de todas as demais iniciativas de reflexão sobre este processo.

Tradicionalmente governada por forças políticas conservadoras, ligadas às oligarquias rurais e às elites urbanas, as quais via de regra pouco se esforçaram ao longo do tempo para construir uma institucionalidade social e política que incluísse os setores populares e que buscasse uma inserção autônoma no sistema internacional, a América Latina viu na ascensão destes recentes governos de esquerda uma exceção em sua trajetória de dois séculos de independência. Como aponta Bolívar Echeverría sobre as nações latino-americanas: " $E l$ aparato institucional republicano fue diseñado en el siglo XIX para organizar la vida de los relativamente pocos propietarios de patrimonio, los únicos ciudadanos verdaderos o admitidos realmente en las repúblicas". (ECHEVERRÍA, 2010).

Isso não quer dizer que no passado não tenha havido tentativas de construção de distintos caminhos, em alguns dos nossos países, que tinham como objetivo superar a condição de meras colônias econômicas de nações mais desenvolvidas e criar sistemas sociais e políticos não tão excludentes como os que temos. Os casos dos governos de viés nacionaldesenvolvimentista de meados do século XX, com todas as críticas que possam ser feitas a eles, não nos deixam mentir a respeito. É inegável, contudo, que a chegada praticamente concomitante ao poder, num intervalo de menos de uma década, de diversos governos progressistas e extração popular constituiu-se num acontecimento novo nesta parte do mundo.

É importante lembrar que o fato não aconteceu em toda a região, mas somente em alguns países. Obviamente cada contexto nacional proporcionou a superação, ou não, da saída (em maior ou menor grau) do modelo de reformas pró-mercado implantado nos anos 1980 e 1990, quando a América Latina foi varrida pela onda neoliberal e seu receituário de redefinição do papel do Estado no desenvolvimento: privatizações de empresas públicas, desregulamentações de toda ordem e abertura comercial, todas com vistas a diminuir os custos de produção, criar oportunidades de negócios para o setor privado e atrair investimentos internacionais.

Os resultados colhidos após a implantação daquelas medidas são amplamente conhecidos: em muitos casos debelou-se o processo inflacionário, em outros ajustou-se as contas públicas, mas à custa do aumento da pobreza, da desigualdade econômica e da exclusão social e do desmantelamento de cadeias produtivas nacionais. Como desdobramento político da nova conjuntura econômica e social, as elites tradicionais de várias nações latinoamericanas não tiveram mais êxito eleitoral, e o que se seguiu foi uma sucessão de vitórias eleitorais das esquerdas: Hugo Chávez (1998) na Venezuela foi a primeira delas, depois acompanhada nos anos seguintes pelas vitórias de Lula (2002) no Brasil, Néstor Kirchner (2003) na Argentina, Tabaré Vásquez (2005) no Uruguai, Evo Morales (2006) na Bolívia, 
Daniel Ortega (2006) na Nicarágua, Rafael Correa (2007) no Equador e Maurício Funes (2009) em El Salvador. E talvez como última e tardia manifestação desta tendência esteja a vitória eleitoral de Luis Guillermo Solís, na Costa Rica, em 2014.

Ainda que existam profundas diferenças entre nossos países e entre os processos que levaram tais setores progressistas ao poder, é importante pensar que para além da causa comum a toda a América Latina, qual seja, o desejo de construção de sociedades mais justas, mais prósperas e mais independentes, o qual tem embalado tantos movimentos políticos há séculos no nosso continente, há também entre nossos povos, nossos países e em todos esses processos a noção de uma casa comum. Qual seja, a América Latina, suas tantas particularidades e seu lugar tão peculiar no mundo. Tanto o lugar historicamente construído, ou atualmente existente, como aquele imaginado e desejado. Neste sentido o Programa Democracias em Revolución, Revoluciones em Democracia se propõe, também, a ser uma iniciativa de pensar o nosso continente a partir de uma perspectiva nossa, latino-americana. Para além de refletir sobre os processos políticos transformadores ocorridos em parte da América Latina nos últimos anos, trata-se também de uma iniciativa de pensar a nossa região a partir de outros paradigmas e outras perspectivas, diferentes daqueles elaborados desde os principais centros do poder econômico, político e ideológico do mundo.

Como afirma Pablo Gentili, é necessário que sejamos nós mesmos os intérpretes de nossa própria realidade (GENTILI, 2014, p. 13). E é necessário também que colaboremos na tarefa de construir esse outro lugar de entendimento do lugar da América Latina no mundo, para a qual nos chama a atenção Boaventura de Sousa Santos naquilo que ele denomina Epistemologias do Sul. Ou seja, a diversidade de conhecimentos, práticas e saberes existentes no conjunto de países e regiões que foram submetidos pelo colonialismo europeu e que nos ajudam a apreender e compreender a realidade por lentes diversas daquelas do modelo capitalista e de sua relação até o presente momento colonial com o mundo. Como ressalta também o sociólogo português, trata-se de pensar que o colonialismo foi, também (e continua a sê-lo), "[...\} um processo de dominação epistemológica, uma relação extremamente desigual de saber-poder que conduziu à supressão de muitas formas de saber próprias dos povos e/ou nações colonizados". (SANTOS, 2009, p. 13)

O Programa debruça-se, também, sobre a complexa questão da relação entre democracia e revolução. A pergunta fundamental aqui é: a democracia ocidental, crescentemente reduzida a seu aspecto formal e procedimental, pode conduzir a transformações radicais numa dada sociedade? A mesma questão, vista por outro ângulo: já os processos revolucionários são redutíveis à questão do voto e da representação indireta em gabinetes e parlamentos? Esta tem sido uma questão que atravessa séculos, opondo liberais de um lado e socialistas de outro. Se para os primeiros a democracia só pode fundar-se na liberdade individual, e esta estaria permanentemente ameaçada pela forte intervenção do Estado na vida social e econômica sob um regime socialista, para os últimos não há condições para a existência da democracia em sociedades pautadas pela mais profunda desigualdade, como ocorreu e continua a ocorrer em inúmeros países capitalistas.

Na perspectiva desta nova epistemologia que se vai construindo desde as experiências de governos de esquerda na América Latina, porém, democracia e revolução começam a surgir como conceitos complementares, muito mais que opostos e inconciliáveis. A experiência prática de processos políticos como os recentemente observados na Bolívia, no Equador e na Venezuela, por exemplo, demonstram que, diferentemente da perspectiva de certas correntes de esquerda manifestada em décadas recentes, não é possível mudar a 
realidade dos povos sem conquistar o Estado. E essa conquista, hoje, em meio a ambientes institucionais onde prevalecem a democracia liberal e a economia de mercado e a construção do socialismo ainda é uma tarefa a ser realizada, só pode se dar por meio do voto e da transformação da realidade através do Estado e da construção de uma outra relação dele com a sociedade. Como ressalta Álvaro Garcia Linera:

La gran enseñanza de América Latina en los últimos diez años es el haber respondido a este debate de manera práctica y haber dicho que es posible cambiar al mundo transformando el Estado, aunque no únicamente haciéndolo se cambia el mundo ¡cuidado con tener una mirada excesivamente estatista de las cosas!-. No obstante, marginarnos de la lucha al interior del Estado, de la transformación de su estructura, es simplemente renunciar a la lucha social y tener una actitud contemplativa hacia las relaciones de dominación en y de la sociedad. En otras palabras, es una invocación a la impotencia política. Lo que ha hecho América Latina es responder de otra manera; há comenzado a transformar el aparato del Estado. Pero ¡ojo!, no solamente há modificado el ámbito del gobierno, porque eso sería simplemente un cambio de gobierno manteniendo intacta la estructura estatal. También ha habido una modificación de las estructuras decisionales del Ejecutivo, una transformación de la participación y presencia social de los sectores populares en los parlamentos, municipios, gobernaciones; una modificación sustancial del Organo Judicial, de la estructura organizativa de la Policía, de las Fuerzas Armadas, la cultura, las tradiciones, los sistemas simbólicos de la sociedad, las legitimidades colectivas. Y cuando sucede eso estamos ante una revolución. Una revolución no es solamente la imagen clásica de unos bolcheviques revolucionarios entrando al Palacio de Invierno con sus armas. Es la visión tradicional de la película, pero es apenas la punta del iceberg. Cuando essa estructura compleja de la máquina relacional llamada Estado es removida y transformada, estamos ante revoluciones políticas. (GARCIA LINERA; RIVADENEIRA; SADER; TORRES, 2015, p. 21)

Pois exatamente é esta a perspectiva pela qual o Programa Democracias en Revolucion, Revoluciones en Democracia entende os processos de transformação política ocorridos em alguns dos nossos países nesta última década e meia. Ainda que incrementais, ainda que pautados em nações que vivem sob e integradas a um sistema econômico capitalista, não parece pouca coisa reformular de cima a baixo as instâncias governativas de nações como Equador e Bolívia, ou retirar da extrema pobreza cerca de 40 milhões de pessoas, como se fez nestes anos no Brasil, ou redefinir de maneira incisiva a distribuição da renda petroleira de um país como a Venezuela, enfrentando a duríssima resistência das elites econômicas e locais e destinando parte significativa destes recursos para combater a histórica dívida social daquele país para com a grande maioria de sua população. Neste sentido lideranças políticas surgidas das urnas, como Hugo Chávez, Néstor e Cristina Kirchner, Lula, Pepe Mujica, Evo Morales e Rafael Correa teriam produzido transformações profundas em seus países a partir da institucionalidade democrática tradicional, a qual estaria em permanente processo de modificação para melhor atender às demandas dos setores populares. Diferentemente dos anos 1960 e 1970, a América Latina já não estaria mais diante da possibilidade única da luta armada como via para a conquista do Estado, mas sim da via eleitoral como instrumento para a sua transformação em direção à construção de sociedades 
mais justas.

Não resta dúvida, porém, de que estes processos são extremamente complexos e plenos de contradições. E nem que houve, entre as várias experiências de governos progressistas da região, uma clara distinção. De um lado há aqueles movimentos em que a radicalização da participação popular foi maior, como na Bolívia, no Equador e na Venezuela. E de outro aqueles onde os acenos de pactuação com outros setores sociais, inclusive os conservadores, foram mais pronunciados, como na Argentina, no Brasil e no Uruguai. Uma das distinções primordiais e fundamentais entre os dois grupos de países diz respeito à criação de condições políticas que levaram à convocação de Assembleias Nacionais Constituintes e a criação de um novo pacto social, mais condizente com a nova correlação de forças presente em cada um dos contextos nacionais. Como ressalta Ramón Torres:

Las revoluciones en democracia pueden ser caracterizadas a partir de algunos aspectos relevantes. Su sentido y alcance se determinan mediante reformas constitucionales que reconocen por primera vez el poder constituyente de los pueblos, conjugan -en plural- la existencia de un sujeto histórico múltiple y protagónico: el poder de la ciudadanía, la soberanía popular basada en el ejercicio de sus derechos y obligaciones. Logran legitimarse y relegitimarse socialmente y generan capacidades de control social sobre el Estado y el mercado. (GARCIA LINERA; RIVADENEIRA; SADER; TORRES, 2015, p. 67)

De fato os processos ocorridos na Venezuela, no Equador e na Bolívia foram fortemente marcados pela promulgação de uma nova Carta Magna, na qual se inscreveram importantes artigos voltados a uma nova concepção de participação popular e da relação entre Estado, sociedade e mercado. Tal fato não aconteceu no Brasil, na Argentina e no Uruguai, nos quais partidos de esquerda venceram eleições e passaram a governar a partir de um ordenamento jurídico e político pré-existente e em grande medida referente a outra configuração de forças sociais muito mais favorável aos setores de elite. Esta é uma questão que demandará, por muito tempo ainda, grande esforço de reflexão por parte dos intelectuais. Teriam sido os governos de esquerda da Argentina, Brasil e Uruguai mais radicais em suas prioridades caso tivessem fundado um novo ordenamento jurídico e político através de processos constituintes? Teriam implantado todas as medidas que implantaram os governos de Bolívia, Equador e Venezuela caso não estivessem alicerçados na legitimidade de novas Constituições?

Em ambos os casos, vale lembrar, nada foi transformado sem enfrentar profundas dificuldades e arraigadíssimas resistências por parte das elites políticas tradicionais. E isso, inclusive, para não mencionar o outro grande fosso a separar as nações latino-americanas no período, entre aquelas que tentaram trilhar um caminho mais à esquerda e as demais, há anos governadas por forças conservadoras, como Chile, Colômbia, Peru e México. E lembre-se, ainda, dos casos de experiências de esquerda moderada que, abatidas por seus adversários, tiveram pouco tempo de vida, como Honduras e Paraguai.

Embora o Brasil possa ser colocado neste grupo de países latino-americanos governados por setores de esquerda, há que se matizar um pouco a experiência do nosso país. O processo de mudanças ocorridas desde 2003, com o governo Lula, pode ter sido o mais grandioso da região se considerado em números absolutos, por exemplo, relativos às políticas 
sociais. Mas provavelmente esteve longe da intensidade política observada em outros países da região. Ao contrário, o governo do PT talvez tenha sido o mais bem-sucedido que o capitalismo brasileiro já conheceu. Retirou cerca de 40 milhões de pessoas da pobreza e integrou-as ao mercado de consumo. Multiplicou os fluxos de comércio do país com outras nações, possibilitou lucros recordes a milhares de empresas, atraiu investimentos estrangeiros como nunca antes havia ocorrido, obteve graus de investimento dos principais bancos e agências de risco mundiais, alcançou o pleno emprego da mão de obra economicamente ativa. Colecionou, enfim, sucessos e elogios mundo afora sem confrontar os grandes interesses de classe no país: as velhas oligarquias regionais, o sistema financeiro, as multinacionais, os sistemas privados de saúde e educação, a grande indústria nacional, a mídia corporativa (em mãos de umas poucas famílias) e o agronegócio de exportação. Ampliou o capitalismo brasileiro sem tensionar questões políticas e sociais não resolvidas há décadas ou mesmo séculos num dos países com os piores índices de desigualdade social do mundo.

A experiência petista também não aprofundou os mecanismos democráticos de participação e não politizou a sociedade. Se os pobres foram elevados alguns degraus acima na pirâmide socioeconômica, isso se fez muito mais na condição de consumidores do que de cidadãos. Embora a sociedade civil brasileira tenha setores fortemente organizados, a maior parte dos indivíduos não vive a democracia cotidianamente, exceção feita aos períodos eleitorais. E isso de fato pouco mudou sob os governos petistas. Pouco se avançou na criação ou no aprofundamento de mecanismos de democracia direta nos últimos anos no Brasil.

A pax lulista, assentada num grande acordo de classes entre os mais ricos e os mais pobres, e beneficiada pelos anos de expansão do saldo da Balança Comercial por conta da demanda chinesa por commodities agrícolas, viabilizou a reeleição de Lula e depois a eleição de Dilma Rousseff, sua sucessora. Acabou consagrado entre muitos analistas o termo "reformismo fraco", para referir-se a um modelo de desenvolvimento levado a cabo por um governo de esquerda que jamais ousou confrontar os interesses do grande capital. Envolvido em denúncias de corrupção, o petismo viu seu eleitorado tradicional, forjado na luta contra a ditadura nos anos 1970, afastar-se, e em seu lugar aproximar-se a enorme massa de despossuídos que tradicionalmente sempre foram cooptados politicamente por práticas clientelistas das oligarquias tradicionais. Tal movimento, o lulismo, resultou numa troca parcial do eleitorado petista, uma espécie de nova configuração ideológica a unir elementos discursivos de direita e de esquerda, como a manutenção da estabilidade econômica e a ação distributiva do Estado (SINGER, 2009, p. 4).

Como um dos inúmeros resultados daquela estratégia política se deu a ascensão despolitizada dos mais pobres, a enaltecer valores individualistas semelhantes aos das classes médias tradicionais. Ali estaria, inclusive, um dos principais combustíveis para as manifestações que eclodiram em várias partes do país a partir de 2013, cobrando num primeiro momento melhores serviços públicos a partir de paradigmas de eficiência do setor privado e, na sequência, criando um crescente caldo de cultura no qual se elegeu, a partir da piora da conjuntura macroeconômica e com o inestimável apoio dos meios de comunicação tradicionais e de setores da oposição de direita, o petismo e os seus valores como um inimigo a ser combatido sem trégua.

As urnas de 2014 deram uma vitória muito apertada ao petismo, através da reeleição da presidente Dilma Rousseff. Mas mostraram também ao país a ascensão política de setores de direita há muito considerados pouco competitivos eleitoralmente. Com Dilma foi eleita uma nova legislatura na Câmara dos Deputados e em parte do Senado, em sua maioria liberal 
em termos de economia, minimalista em relação ao papel do Estado como provedor de políticas de bem-estar, conservadora em termos de costumes e questões morais, com destaque para a grande presença de representantes do agronegócio, de igrejas evangélicas e da indústria das armas.

Algo, nesse sentido, parece ter dado errado à estratégia petista de buscar a conciliação permanente com setores conservadores, diferentemente do que se viu em outros países latinoamericanos que têm sido ou foram governados pela esquerda nos últimos anos. Apesar disso e do crescimento recente do peso político da direita brasileira, o país vive atualmente o florescimento de forças progressistas diversas, não-alinhadas ao petismo e situadas inclusive à esquerda deste. Há toda uma nova geração de movimentos sociais, muitos dos quais de base identitária, como gênero, juventude, orientação sexual, etnia etc., ou ligados a temáticas da reforma urbana, da reforma agrária e do meio ambiente, que têm ganhado maior projeção no debate público e podem vir a constituir-se como alternativas de poder no médio e longo prazos.

O caso brasileiro não foge à regra, que de resto se observa em todos os demais países latino-americanos que passaram a ser governados pela esquerda na última década e meia, de ser repleto de contradições, conforme já mencionamos. É interessante observar que ao mesmo tempo em que tais governos são acossados pelas forças conservadoras, são também pressionados por setores progressistas que demandam o aprofundamento da democracia, o combate às desigualdades e a quaisquer tentativas de pacto com a direita. Não à toa Evo Morales na Bolívia e Rafael Correa no Equador encontram em segmentos do movimento indígena duras críticas a alguns pilares de seus governos. Não à toa Cristina Kirchner deixou a presidência da Argentina após um difícil processo eleitoral contra a direita e Nicolás Maduro se vê às voltas com serí́ssimas dificuldades políticas e econômicas. Refletir sobre as contradições destas experiências de setores progressistas que se tornaram governo na América Latina, e suas tensões com seus inimigos à direita e seus adversários à esquerda, é uma importante tarefa do Programa Democracias en Revolución, Revoluciones en Democracia. Mais que isso, inclusive, é sua tarefa pensar a respeito do novo cenário que se desenha no continente, com a possibilidade de uma nova guinada política e ideológica em vários países, desta vez à direita, que já se observa após a eleição de Mauricio Macri na Argentina, a derrubada de Dilma Rousseff no Brasil, a difícil situação do governo Maduro na Venezuela e o fortalecimento da oposição conservadora no Equador e em El Salvador.

Metodologicamente o Programa é dividido em eixos temáticos e eixos nacionais, a partir das prioridades escolhidas por cada um dos pontos da rede, formado por pesquisadores de distintas universidades de um mesmo país. As temáticas da Política, da Economia, da Cultura e do Meio Ambiente, porém, formam os pilares nos quais se assentam todos os vários eixos de pesquisa. Na temática da Política encontra-se, obviamente, a discussão sobre democracia e participação, indo da questão da organização autônoma dos movimentos sociais à maior abertura das instâncias governamentais à interlocução com a sociedade, priorizandose também a reflexão sobre antigas e novas gerações de Direitos, mais ou menos consagradas e garantidas a maiores ou menores contingentes da população de país a país. Na temática da Economia discute-se o papel do Estado na indução do desenvolvimento econômico e do Bem Estar Social, bem como de suas relações com as instituições do mercado, como as corporações empresariais e os fluxos globais do capital.

A temática da Cultura pesquisa as formas, práticas e saberes dos distintos povos da região, tanto como forma de resistência à dominação epistemológica emanada desde os 
centros mais ricos do capitalismo, quanto como maneiras de construir-se, a partir da experiência de grupos urbanos e rurais estigmatizados e marginalizados, um outro viver social. Na temática do Meio Ambiente ressalta-se o enorme potencial de biodiversidade e de energia existente na América Latina, e as formas de conciliar sua preservação com o desenvolvimento social, o combate à pobreza e a preservação das práticas e saberes dos povos originários. Nos distintos países participantes do Programa foram escolhidos eixos de investigação diferentes, e em alguns casos mais específicos, tais como: Reforma do Estado (num sentido democratizante); Políticas de Desenvolvimento Científico e Tecnológico; Economia Social; Buen Vivir; Segurança e Forças Armadas; Integração Regional; Democratização dos Meios de Comunicação.

Os resultados alcançados pelo Programa até aqui remetem à formação de uma ampla rede de pesquisadores, trabalhando em universidades na América Latina e também fora dela, interessados no aprofundamento da compreensão sobre os processos políticos ocorridos em nossa região desde a virada do século. A perspectiva interdisciplinar para a análise destes fenômenos, resultando num esforço intelectual compartilhado e convergente, é o principal logro obtido pelo Programa. Encontros acadêmicos, debates em universidades e nos meios de comunicação, publicação de artigos e livros, fortalecimento da temática de América Latina nas universidades participantes da rede e a permanente abertura para a participação de novos pesquisadores, inclusive em início da trajetória acadêmica, são os principais resultados até o momento alcançados.

\section{BIBLIOGRAFIA}

ECHEVERRÍA, Bolívar. América Latina: 200 años de fatalidad. Disponível em http://www.sinpermiso.info/textos/amrica-latina-200-aos-de-fatalidad, 12 abril 2010. Acessado em 01/07/2016.

GARCIA LINERA, Alvaro; RIVADENEIRA, Gabriela; SADER, Emir; TORRES, Ramon (Orgs.). Democracias en Revolución, Revoluciones en Democracia. La Paz: Centro de Investigaciones Sociales - Vice Presidencia, 2015.

GENTILI, Pablo. Pensar el mundo desde América Latina. Crítica y Emancipación - Revista Latinoamericana de Ciencias Sociales, n. 12, v. 1, p. 11-16, 2014.

SANTOS, Boaventura de Souza; MENEZES, Maria Paula (Orgs.). Epistemologias do Sul. Coimbra: CES; Alamedina Editorial, 2009.

SINGER, André. Raízes sociais e ideológicas do Lulismo. Novos Estudos Cebrap, n. 85, novembro 2009. 